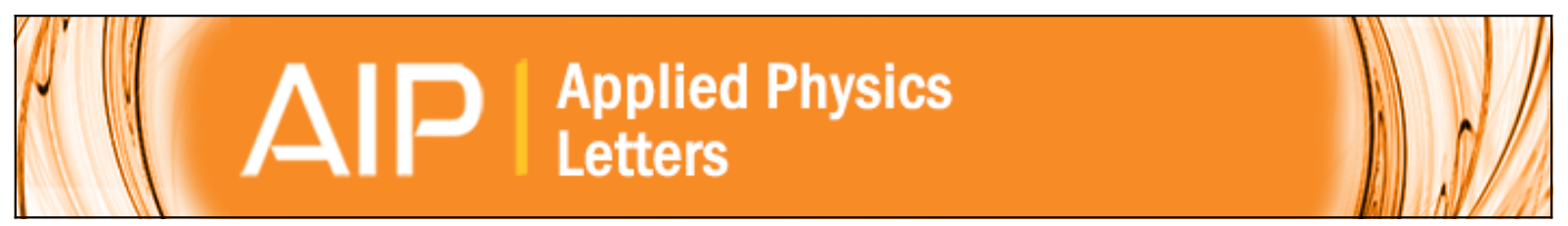

Interband cascade lasers with room temperature threshold current densities below $\mathbf{1 0 0}$ A/cm2

Robert Weih, Martin Kamp, and Sven Höfling

Citation: Applied Physics Letters 102, 231123 (2013); doi: 10.1063/1.4811133

View online: http://dx.doi.org/10.1063/1.4811133

View Table of Contents: http://scitation.aip.org/content/aip/journal/apl/102/23?ver=pdfcov

Published by the AIP Publishing

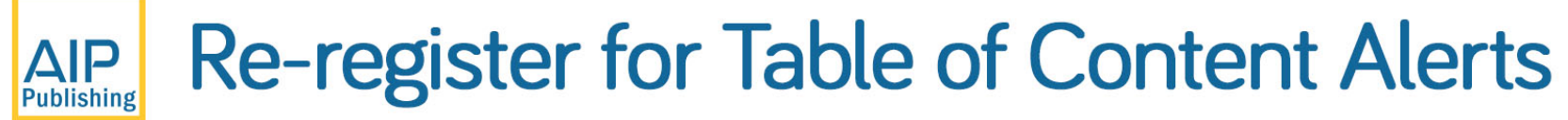




\title{
Interband cascade lasers with room temperature threshold current densities below $100 \mathrm{~A} / \mathrm{cm}^{2}$
}

\author{
Robert Weih, Martin Kamp, and Sven Höfling ${ }^{\text {a) }}$ \\ Technische Physik, Physikalisches Institut and Wilhelm Conrad Röntgen-Research Center for Complex \\ Material Systems, Universität Würzburg, Am Hubland, D-97074 Würzburg, Germany
}

(Received 1 February 2013; accepted 29 May 2013; published online 13 June 2013)

\begin{abstract}
Interband Cascade Lasers (ICLs) with threshold current densities below $100 \mathrm{~A} / \mathrm{cm}^{2}$ in pulsed operation at room temperature are presented. The laser structure comprises 10 active stages of $41 \mathrm{~nm}$ length, each stage containing a W-quantum well active region for emission in the spectral region around $3.6 \mu \mathrm{m}$. A comparison of devices with 6 and 10 stages shows that the latter have a reduced threshold due to an increased optical confinement factor, very competitive threshold power densities of $428 \mathrm{~W} \mathrm{~cm} \mathrm{~cm}^{-2}$ despite an increased threshold voltage and large differential slope efficiencies of $1390 \mathrm{~mW} / \mathrm{A}$. For a narrow ridge device, continuous wave operation is observed up to $65^{\circ}$ C. (C) 2013 AIP Publishing LLC. [http://dx.doi.org/10.1063/1.4811133]
\end{abstract}

Compact and robust semiconductor lasers emitting in the mid infrared region are required for various applications like chemical sensing, free-space communications, or countermeasures. Over the last years, interband cascade lasers (ICLs) ${ }^{1}$ have shown their ability to cover the wavelength region between 3.4 and $5.6 \mu \mathrm{m}$ with devices operating in continuous wave $(\mathrm{CW})$ mode at room temperature. ${ }^{2,3}$ This was mainly achieved by a reduction of the threshold current density, which resulted from various design changes and optimal doping of the active region as well as the waveguide. A major breakthrough was reported in 2008: the first cw operation at room temperature. ${ }^{4}$ A prerequisite of this milestone was notable lower threshold current densities around $400 \mathrm{~A} / \mathrm{cm}^{2}$, achieved by a reduction of the doping levels in the optical claddings and separate confinement layers (SCLs). Further remarkable improvements were obtained via rebalancing of internally generated carriers with heavily doped electron injector regions ${ }^{2}$ and further reduced doping densities in different functional parts, ${ }^{5}$ reducing threshold current densities from $167 \mathrm{~A} / \mathrm{cm}^{2}$ in 2011 to so far best values of $134 \mathrm{~A} / \mathrm{cm}^{2}$ in 2012 . In this letter, we report a further reduction of the threshold current densities to unprecedented values below $100 \mathrm{~A} / \mathrm{cm}^{2}$. This is more than an order of magnitude lower than best values (around $1100 \mathrm{~A} / \mathrm{cm}^{2}$ ) reported for state-of-the-art quantum cascade ${ }^{6-8}$ and quantum well diode lasers ${ }^{9}$ in this spectral range.

All devices investigated in this work were grown on Tedoped $\left(1.0 \times 10^{18} \mathrm{~cm}^{-3}\right) \mathrm{GaSb}$ wafers in an EIKO molecular beam epitaxy machine. The machine is equipped with solid sources for the group-III elements and valved cracker cells for both arsenic and antimony. A dual dopant cell incorporating $\mathrm{Si}$ and Te was used for doping. The substrate temperature was monitored during growth by a pyrometer. Prior to the epitaxy, the wafer was baked in a pre-chamber for half an hour at $300^{\circ} \mathrm{C}$. After transferring the wafer to the main chamber, the oxide was removed at $580^{\circ} \mathrm{C}$ under $\mathrm{Sb}$ flux for stabilization. Subsequently, the growth was initiated with a $200 \mathrm{~nm}$ thick Te-doped $\left(1.5 \times 10^{18} \mathrm{~cm}^{-3}\right) \mathrm{GaSb}$ buffer layer

${ }^{\text {a)} E l e c t r o n i c ~ m a i l: ~ s v e n . h o e f l i n g @ p h y s i k . u n i-w u e r z b u r g . d e . ~}$ grown at $485^{\circ} \mathrm{C}$. This buffer was followed by an InAs/AlSb transition region (grown at $450{ }^{\circ} \mathrm{C}$ ) to smoothen the effective conduction band profile at the transition to the lower cladding layer. The thickness of the Si-doped $\left(8 \times 10^{17} \mathrm{~cm}^{-3}\right)$ InAslayers was increased stepwise from 1.25 to $2.43 \mathrm{~nm}$ while the thickness of each directly adjacent AlSb layer was increased from 1.13 to $2.30 \mathrm{~nm}$ to maintain a constant layer pair ratio for strain compensation. The total thickness of the transition layer amounts to $40.6 \mathrm{~nm}$. In order to minimize losses due to optical mode leakage into the substrate, a thick superlattice (SL) lower cladding was grown, which comprised 685 InAs/ $\mathrm{AlSb}$ repetitions with a period of $4.73 \mathrm{~nm}$. Mixed interfaces were used and strain compensation was adjusted via the group-V flux ratio. The Si-doping density of the InAs layers was decreased from $8 \times 10^{17} \mathrm{~cm}^{-3}$ to $2 \times 10^{17} \mathrm{~cm}^{-3}$ towards the core of the structure to reduce free-carrier losses due to the overlap of the optical mode with highly doped regions. After another InAs/AlSb transition region that is designed like the previously described one with decreasing layer thicknesses and InAs layers doped with Si to $2 \times 10^{17} \mathrm{~cm}^{-3}$, a $200 \mathrm{~nm}$ thick GaSb SCL was grown at $485^{\circ} \mathrm{C}$ with a Tedoping density of $3 \times 10^{17} \mathrm{~cm}^{-3}$. The high refractive index of the GaSb layer serves to concentrate the optical mode in the center of the structure. For that purpose, the transition layer connecting the SCL and the first cascade was designed somewhat different from the ones between the cladding and the SCL. In order to increase the average refractive index in this region, mixed $\mathrm{AlSb} / \mathrm{GaSb}(0.75 \mathrm{~nm} / 0.75 \mathrm{~nm})$ barriers were inserted. While the thickness of the undoped barriers remained constant, the InAs (Si-doped to $5.0 \times 10^{18} \mathrm{~cm}^{-3}$ ) layer thickness was increased stepwise from $1.0 \mathrm{~nm}$ to $1.7 \mathrm{~nm}$, resulting in a total transition layer thickness of $23.6 \mathrm{~nm}$. Right after the SCL growth, the substrate temperature was ramped down to $450{ }^{\circ} \mathrm{C}$. The cascade region published in Ref. 2 was used for the active stages. It comprised the following layer sequence: $2.5 \mathrm{~nm} \mathrm{AlSb} / 1.7 \mathrm{~nm} \mathrm{InAs} /$ $3.0 \mathrm{~nm} \mathrm{Ga}{ }_{0.65} \mathrm{In}_{0.35} \mathrm{Sb} / 1.4 \mathrm{~nm}$ InAs/1.0 nm AlSb/3.0 nm GaSb/ $1.0 \mathrm{~nm} \mathrm{AlSb} / 4.5 \mathrm{~nm} \mathrm{GaSb} / 2.5 \mathrm{~nm}$ AlSb/4.2 nm InAs/1.2 nm $\mathrm{AlSb} / 3.2 \mathrm{~nm} \mathrm{InAs} / 1.2 \mathrm{~nm} \mathrm{AlSb} / 2.5 \mathrm{~nm} \mathrm{InAs} / 1.2 \mathrm{~nm} \mathrm{AlSb} /$ $2.0 \mathrm{~nm} \mathrm{InAs} / 1.2 \mathrm{~nm} \mathrm{AlSb/1.7} \mathrm{nm} \mathrm{InAs/1.2} \mathrm{nm} \mathrm{AlSb/1.7} \mathrm{nm}$ 
InAs. In order to rebalance the internally generated carriers, the four inner electron injector quantum wells were heavily n-type doped with Si to $5 \times 10^{18} \mathrm{~cm}^{-3}$. This doping concentration has previously shown to provide optimal performance for this active region design with regard to lowest threshold current densities and turn-on voltages. The InAs-quantum wells of the active W-type quantum well were designed to yield a laser emission wavelength around $3.6 \mu \mathrm{m}$, which can be applied to formaldehyde detection ${ }^{10}$ utilizing an even more intense absorption line than the one at $3.49 \mu \mathrm{m}$ that has been previously used. ${ }^{11}$ ICLs with 6 and 10 stages were grown for comparison. The rest of the structure was grown in a symmetrical fashion with the upper cladding region being somewhat less thick (400 InAs/AlSb-SL repetitions). The growth was finalized with a $20 \mathrm{~nm}$ thick InAs contact layer, which was heavily Si-doped $\left(5 \times 10^{18} \mathrm{~cm}^{-3}\right)$ to reduce the contact resistance.

Figure 1 shows a comparison of the optical mode profiles for ICL structures with 6 and 10 cascades. The refractive index of every layer in the active region was considered in the calculations even though it is displayed constant in the graph. Since the entire active region with a larger cascade number is wider, the relative optical mode intensity is about $10 \%$ lower for this structure. However, if the overlap of the optical mode with the different regions is compared, an improvement of the optical confinement factors can be found. In the case of the 6 stage ICL, the confinement factor of the active region $\left(\Gamma_{\mathrm{a}}\right)$ is 0.214 , while the confinement factor of the SL-claddings $\left(\Gamma_{\mathrm{c}}\right)$ is 0.463 . For the 10 cascade laser, $\Gamma_{\mathrm{a}}$ increases to 0.285 and $\Gamma_{\mathrm{c}}$ decreases to 0.414 . Hence, the optical mode overlap with the active region becomes larger while the overlap with the SL-claddings decreases with a higher stage number, as expected. The confinement factor of the SCL layers $\Gamma_{\mathrm{SCL}}$ does not change significantly.

Broad area and narrow ridge lasers were fabricated from both samples for characterization and comparison of basic laser parameters and continuous wave performance. An inductively coupled plasma based process was used to etch down through the active region and the lower SCL. The sample was then dipped into a phosphoric acid containing etchant for $15 \mathrm{~s}$ to reduce the damage from the dry etch.

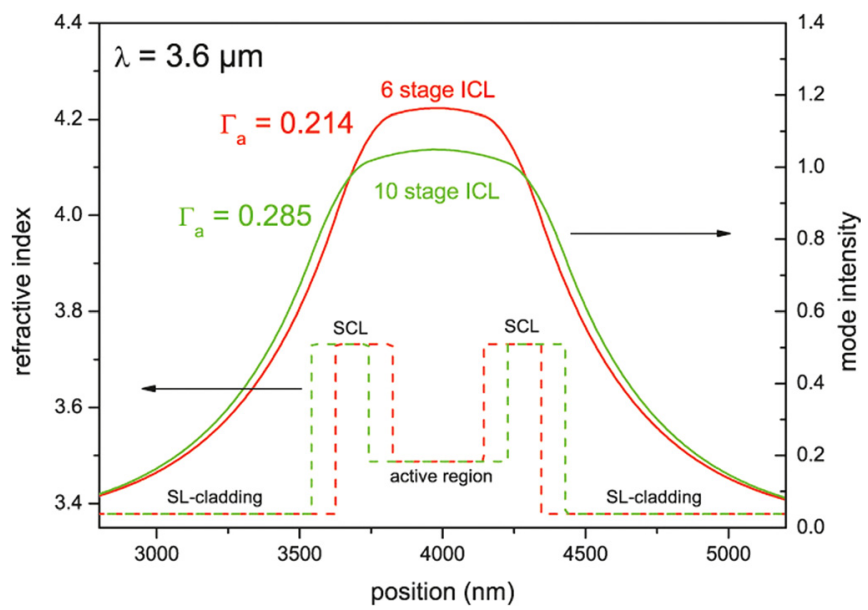

FIG. 1. Refractive index profile and optical laser mode intensity along the growth direction for ICLs with 6 and 10 stages emitting at a wavelength of $3.6 \mu \mathrm{m}$.

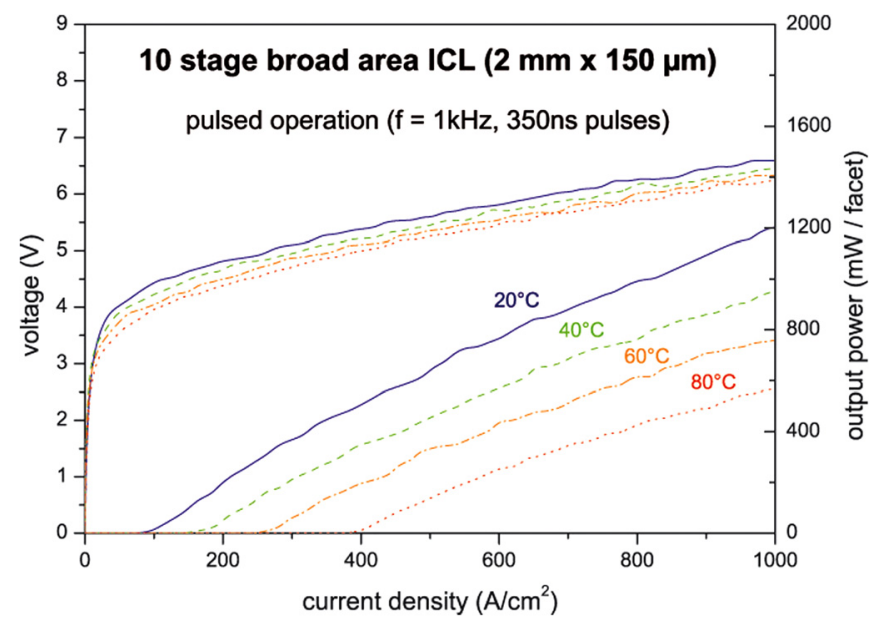

FIG. 2. Pulsed light-current and current-voltage curves at different temperatures $\left(20,40,60\right.$, and $\left.80^{\circ} \mathrm{C}\right)$ for a $2 \mathrm{~mm}$ long and $150 \mu \mathrm{m}$ wide broad area ICL.

Subsequently, $200 \mathrm{~nm}$ of each $\mathrm{Si}_{3} \mathrm{~N}_{4}$ and $\mathrm{SiO}_{2}$ were sputtered on the ridges for sidewall passivation. The isolation layer was removed on the top of the lasers by a dry etch step and a Ti/Pt/Au-contact was deposited. For heat removal, the narrow ridges were electroplated with approximately $5 \mu \mathrm{m}$ of gold, while cleaving lanes without any electroplated gold were left every $600 \mathrm{~nm}$. Afterwards, the substrate was thinned to $150 \mu \mathrm{m}$ and an $\mathrm{Au} / \mathrm{AuGe}$ bottom contact was evaporated. Finally, the sample was annealed for $30 \mathrm{~s}$ at $260^{\circ} \mathrm{C}$ and cleaved into laser resonators of defined length. The narrow ridge lasers were additionally mounted with In-solder to copper heat sinks.

To minimize the heating of samples, the lasers were measured using $350 \mathrm{~ns}$ pulses at a repetition rate of $1 \mathrm{kHz}$. Figure 2 shows the electrical and the optical characteristics of the 10 cascade device for different temperatures between $20^{\circ} \mathrm{C}$ and $80^{\circ} \mathrm{C}$. Due to the temperature caused change in the bandgaps and the resulting redshift of the emission, the voltage for the same current values decreases at higher temperatures. In Figure 3, the temperature dependent threshold current densities $\left(\mathrm{J}_{\mathrm{th}}\right)$ are shown. The 6 cascade device displays $\mathrm{J}_{\mathrm{th}}=179 \mathrm{~A} / \mathrm{cm}^{2}$

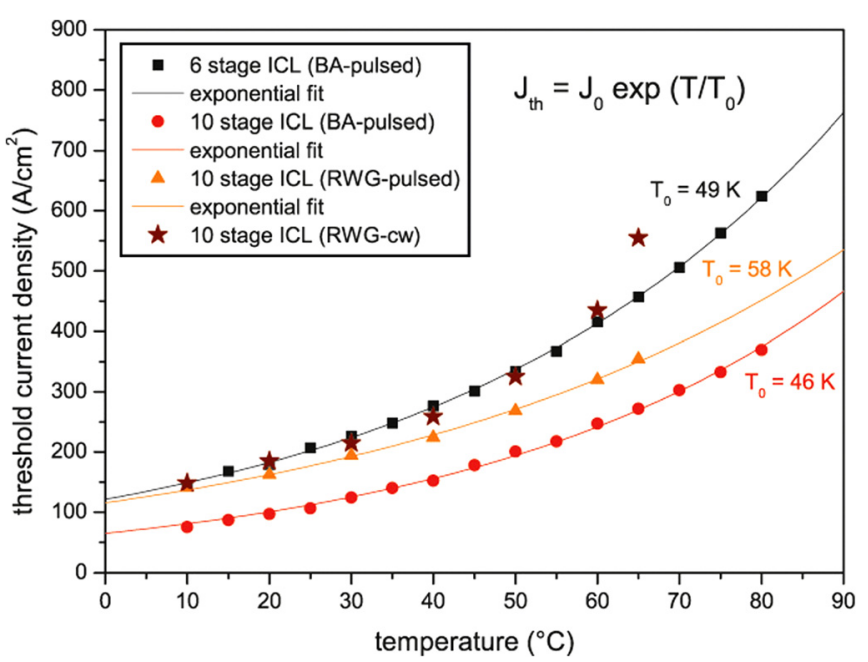

FIG. 3. Temperature dependent threshold current density for the ICLs with 6 and 10 cascades in the temperature range from $10^{\circ} \mathrm{C}$ to $80^{\circ} \mathrm{C}$. Also shown is the temperature behavior for a 10 stage narrow ridge device $(3 \mathrm{~mm} \times 10.8 \mu \mathrm{m})$ in pulsed and continuous wave operation. 
6 stage ICL

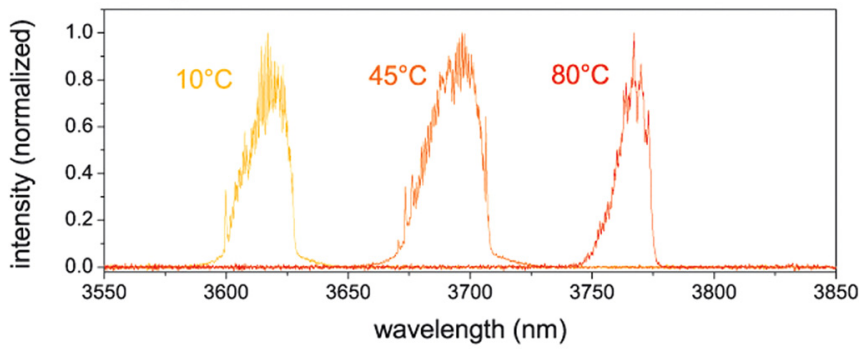

10 stage ICL

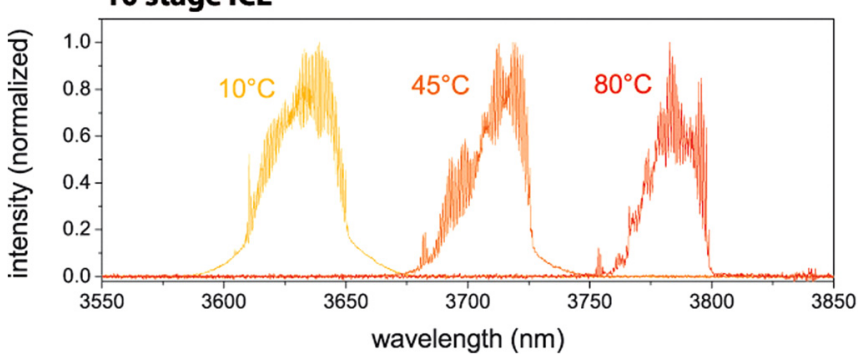

FIG. 4. Spectra at $10^{\circ} \mathrm{C}, 45^{\circ} \mathrm{C}$, and $80^{\circ} \mathrm{C}$ of both broad area $(2 \mathrm{~mm} \times 150 \mu \mathrm{m})$ devices (6 and 10 cascades). The lasers show almost the same emission wavelength and temperature tuning behavior.

at $20^{\circ} \mathrm{C}$ compared with $\mathrm{J}_{\mathrm{th}}=98 \mathrm{~A} / \mathrm{cm}^{2}$ for the 10 cascade device at the same temperature, which represents the lowest $\mathrm{J}_{\text {th }}$ reported for a semiconductor laser in this wavelength region. This result can be attributed to the different confinement factors as well as the increased quantum efficiency. The characteristic temperature $\left(\mathrm{T}_{0}\right)$ did not change significantly when the number of cascades was increased. It was determined to $\mathrm{T}_{0}=49$ and $\mathrm{T}_{0}=46$, respectively, representing state-of-the-art temperature stability. ${ }^{5}$ Figure 4 shows the lasing spectra for both structures at different temperatures. The temperature dependent wavelength shift is determined to be approximately $2 \mathrm{~nm} / \mathrm{K}$. Caused by the higher number of stages, the threshold voltage $\left(\mathrm{V}_{\mathrm{th}}\right)$ is higher for the 10 cascade device. Room temperature onset voltages $\left(\mathrm{V}_{0}\right)$ of $2.3 \mathrm{~V}$ (6 cascades) and $4.2 \mathrm{~V}$ (10 cascades) were determined by fits to the current voltage characteristic. This corresponds to voltage efficiencies of $90 \%$ and $82 \%$, respectively. Nevertheless, the threshold power density $\left(\mathrm{P}_{\mathrm{th}}\right)$ of the ICLs decreases from $505 \mathrm{~W} / \mathrm{cm}^{2}$ to $428 \mathrm{~W} /$ $\mathrm{cm}^{2}$, when the cascade number is increased. Even though values of $315 \mathrm{~W} / \mathrm{cm}^{2}$ have been reported for 5 cascaded ICLs with reduced loss due to notably lower SCL doping, ${ }^{12}$ this clearly depicts the advantageous integration of additional cascade numbers. Furthermore, the total differential slope efficiencies could be increased from $780 \mathrm{~mW} / \mathrm{A}$ for the 6 stage device to $1390 \mathrm{~mW} / \mathrm{A}$ for the 10 stage device at $20^{\circ} \mathrm{C}$. This corresponds to external quantum efficiencies $\left(\eta_{\mathrm{e}}\right)$ of $38.4 \%$ and $41.0 \%$ per stage, respectively. These values are comparable to earlier published data. ${ }^{12}$

A $10.8 \mu \mathrm{m}$ wide ridge device with a high reflectivity coated back facet operated up to $65^{\circ} \mathrm{C}$ in cw-mode. At room temperature, $\mathrm{J}_{\text {th }}$ was $185 \mathrm{~A} / \mathrm{cm}^{2}$ and the laser emitted more than $28 \mathrm{~mW}$ of optical power. Figure 5 shows the temperature dependent characteristics of the device. Both the maximum operation temperature and the maximum output power are limited by thermal rollover. The nonlinear output characteristic and a wavelength shift from $3.62 \mu \mathrm{m}$ at $10^{\circ} \mathrm{C}$ to $3.73 \mu \mathrm{m}$ at $50{ }^{\circ} \mathrm{C}$ near threshold with a corresponding rate of $2.8 \mathrm{~nm} / \mathrm{K}$

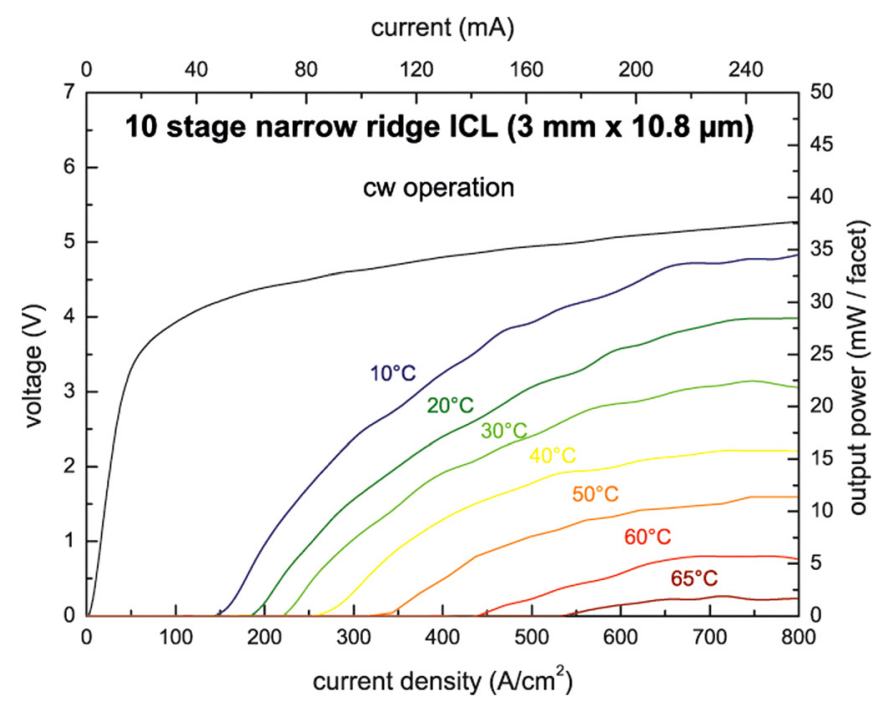

FIG. 5. Continuous wave light-current characteristic for a $10.8 \mu \mathrm{m}$ wide and $3 \mathrm{~mm}$ long ICL device with a high-reflection (HR) coated back facet at several temperatures between $10^{\circ} \mathrm{C}$ and $65^{\circ} \mathrm{C}$. The current-voltage curve was measured at $20^{\circ} \mathrm{C}$.

indicate strong heating of the active region with increasing current. One more indicator is the different temperature dependent $\mathrm{J}_{\text {th }}$ behaviour in pulsed and cw-operation shown in the inset of Figure 3. While at low duty cycles a $\mathrm{T}_{0}$ of $58 \mathrm{~K}$ could be extracted, $\mathrm{J}_{\text {th }}$ increases very fast with temperature in $\mathrm{cw}$ mode. Also note the higher threshold current densities for the 10 stage narrow ridge compared with the broad area device THAT are mainly attributable to defect induced current leakage and surface recombination. Also note the higher threshold current densities for the 10 stage narrow ridge compared with the broad area device, mainly attributable to defect induced current leakage and surface recombination. By comparing the temperature dependent red shift of Fabry Perot modes in pulsed operation with the current induced shift under $\mathrm{cw}$ operation, a room temperature thermal resistivity of $12.8 \mathrm{Kcm}^{2} / \mathrm{kW}$ was determined, which is about three times higher than thermal resistivities reported elsewhere. ${ }^{13}$ This is likely due to different mounting techniques and the almost $3.4 \mu \mathrm{m}$ thick lower SL-cladding, which has a poor thermal conductivity of approximately $3 \mathrm{~W} / \mathrm{mK} .{ }^{14}$ In prospective ICL growth runs, this effect can possibly be avoided with a thinner cladding region. Therefore, the SCL layers would have to be thickened in order to decrease the penetration of the optical mode into the cladding layers and avoid additional losses due to mode leakage into the substrate. Nevertheless, the advantage of the higher stage number can be recognized looking at the steep differential power slope slightly above threshold. At $20^{\circ} \mathrm{C}$, the slope efficiency is as high as $315 \mathrm{~mW} / \mathrm{A}$.

We were able to reduce the room temperature threshold current density of ICLs to unprecedented values below $\mathrm{J}_{\mathrm{th}}<100 \mathrm{~A} / \mathrm{cm}^{2}$. It is shown that the lower $\mathrm{J}_{\text {th }}$ of a 10-stage instead of a 6-stage device overcomes the increase in $V_{\text {th }}$ in terms of the figure of merit $\mathrm{P}_{\text {th }}$, which could be reduced by more than $15 \%$. This makes ICLs with a large number of gain stages interesting for applications that require low power consumption. With four additional stages, the differential slope efficiency increases by $78 \%$ and the optical output power at 
the same injection current increases as well, making ICLs with a high number of stages attractive for high power applications. While low power consumption is possible, the performance obtained for larger number of stages makes ICLs promising to come also closer to the high power performance obtained by quantum cascade lasers. In terms of continuous wave performance, a $10.8 \mu \mathrm{m}$ wide laser ridge emitted more than $28 \mathrm{~mW}$ of output power at room temperature.

We are very grateful to the German Ministry of Education and Research for financial support of this work (FKZ: 13N12440). We also would like to thank A. Wolf, M. Wagenbrenner, S. Handel, and T. Steinl for assistance during sample preparation, growth, and characterization and $\mathrm{M}$. Dallner for fruitful discussions.

${ }^{1}$ R. Q. Yang, Superlattices Microstruct. 17(1), 77 (1995).

${ }^{2}$ I. Vurgaftman, W. W. Bewley, C. L. Canedy, C. S. Kim, M. Kim, C. D. Merritt, J. Abell, J. R. Lindle, and J. R. Meyer, Nat. Commun. 2, 585 (2011).
${ }^{3}$ W. W. Bewley, C. L. Canedy, C. S. Kim, M. Kim, C. D. Merritt, J. Abell, I. Vurgaftman, and J. R. Meyer, Opt. Express 20(3), 3235 (2012).

${ }^{4}$ M. Kim, C. L. Canedy, W. W. Bewley, C. S. Kim, J. R. Lindle, J. Abell, I. Vurgaftman, and J. R. Meyer; Appl. Phys. Lett. 92, 191110 (2008).

${ }^{5}$ W. W. Bewley, C. D. Merritt, C. S. Kim, C. L. Canedy, I. Vurgaftman, J. Abell, and J. R. Meyer, Proc. SPIE 8374, 83740H (2012).

${ }^{6}$ N. Bandyopadhyay, Y. Bai, B. Gokden, A. Myzaferi, S. Tsao, S. Slivken, and M. Razeghi, Appl. Phys. Lett. 97, 131117 (2010).

${ }^{7}$ N. Bandyopadhyay, S. Slivken, Y. Bai, and M. Razeghi, Appl. Phys. Lett. 100, 212104 (2012).

${ }^{8}$ N. Bandyopadhyay, Y. Bai, S. Tsao, S. Nida, S. Slivken, and M. Razeghi, Appl. Phys. Lett. 101, 241110 (2012).

${ }^{9}$ K. Vizbaras and M.-C. Amann, Electron. Lett. 47(17), 980 (2011).

${ }^{10}$ S. W. Sharpe, T. J. Johnson, R. L. Sams, P. M. Chu, G. C. Rhoderick, and P. A. Johnson, Appl. Spectrosc. 58, 1452-1461 (2004).

${ }^{11}$ S. Lundqvist, P. Kluczynski, R. Weih, M. V. Edlinger, L. Nähle, M. Fischer, A. Bauer, S. Höfling, and J. Köth, Appl. Opt. 51(25), 6009 (2012).

${ }^{12}$ W. W. Bewley, C. L. Canedy, C. S. Kim, M. Kim, C. D. Merritt, J. Abell, I. Vurgaftman, and J. R. Meyer, Opt. Express 20(19), 20894 (2012).

${ }^{13}$ C. S. Kim, M. Kim, W. W. Bewley, J. R. Lindle, C. L. Canedy, J. Abell, I. Vurgaftman, and J. R. Meyer, Appl. Phys. Lett. 95, 231103 (2009).

${ }^{14}$ T. Borca-Tasciuc, D. Achimov, W. L. Liu, G. Chen, H.-W. Ren, C.-H. Lin, and S. S. Pei, Microscale Thermophys. Eng. 5, 225 (2001). 